\title{
Optimal Design of Phase Change Thermal Storage Device for A
}

\section{DX-SAHPV System}

\author{
Guo-Hua Shi ${ }^{1, a^{*}}$, Jia Wang ${ }^{1, b}$, Xianliang Yang ${ }^{1, c}$, Min Tang ${ }^{1, d}$, \\ Shengnan $\operatorname{Tian}^{1, e}$ and Jinrui Zhang ${ }^{2, f}$ \\ ${ }^{1}$ North China Electric Power University, Department of Power Engineering, Baoding, China \\ ${ }^{2}$ Henan electric Power Survey \& Design Institute, Zhengzhou, China \\ a ${ }^{*}$ Corresponding author, lucksgh@126.com, ${ }^{b}$ jiawangha@outlook.com, ${ }^{c}$ yxl15820@163.com, \\ d Ik doudoutang@163.com, ${ }^{\text {e } 1509655789 @ q q . c o m},{ }^{f}$ 17343605@qq.com,
}

\begin{abstract}
Keywords: Solar assisted heat pump, Phase change heat storage, Energy efficiency, Fluent, Optimal design.

Abstract. In order to improve the utilization of solar energy and to reduce the energy consumption of an auxiliary heat source, this study investigates a phase change heat storage device for an LPG vaporization system utilizing solar assisted heat pump (DX-SAHPV). In this study, paraffin was chosen as the phase change material (PCM). The structure of phase change heat storage device was determined by the simulation using the Fluent software. The optimal radius of each PCM sphere is $60 \mathrm{~mm}$. The phase change rates and corresponding temperature distributions were also analyzed during the thermal storage process and the release process, respectively. Finally, an economic analysis was made to investigate the optimal heat storage capacity of the PCM device.
\end{abstract}

\section{Introduction}

Liquefied petroleum gas (LPG) is generally vaporized from the liquid to the vapor by hot water generated by electric or fossil fuel-fired water heaters. However, this conventional vaporization has led to large energy consumption and serious pollutant emissions, which conflicts with Chinese current energy conservation policies. In order to solve the problem, an LPG vaporization system utilizing direct-expansion solar assisted heat pump (DX-SAHPV) was proposed and analyzed in [1]. The results show that vaporizing LPG by solar assisted heat pump has a good thermal performance and is contributed to energy conservation and environmental protection.

However, the DX-SAHPV system still consumes some LPG to produce hot water by an auxiliary gas-fired water heater under the poor weather conditions. Setting up a thermal storage device in a solar thermal utilization system can improve its performance [2]. The latent heat storage has many advantages, such as high heat storage density, constant temperature during the heat storage/release process and small size, so it is widely used in solar thermal utilization systems $[3,4]$.

This paper proposes a new DX-SAHPV system with a thermal storage using PCM. The optimization design of the phase change thermal storage device is carried out as follows: the selection of PCM, the optimal size of each PCM unit, the structure, the heat storage cycle and the heat capacity of the heat storage device. 


\section{System description}

Fig. 1 shows the schematic diagram of a DX-SAHPV system with a phase change storage that is introduced in detail in [5]). There are five operation modes that are listed in Table 1.

Table1 Operation modes of DX-SAHPV with PCM and their operating cinditions

Brief description of mode

The refrigerant circulating process is 1-2-3-5-1; phase change hea

storage water tank, vaporizer, and auxiliary heat source off, water tank storages heat.

The refrigerant circulating process is 1-2-4-5-1; water tank,

vaporizer and auxiliary heat source off , phase change heat storage water tank storages heat

LiquidLPG in the cylinders flows the vaporizer and absorbs heat to become LPG vapour.

\section{Operation conditions}

If the water temperature in the water tank is lower than the lower setting pint, the system runs in M1.
In case of low gas load, the natural vaporization capacity of LPG cylinders can meet the gas load demand. The DX-SAHP is in working condition when the solar radiation intensity is not zero.
If the water temperature in the water tank exceeds the upper setting point and the temperature of PCM is lower than the phase change temperature, the system runs in M2.
In case of peak gas load, the natural vaporization capacity of LPG cylinders is not enough to meet the gas load demand. The system runs in M3

When the heat generated by DX-SAHP is less, and the natural vaporization capacity of LPG cylinders and the heat stored in the water tank and phase change heat storage water tank is not enough to meet the gas load demand, the system runs in M4

When there are faults happening in two water tanks, the sytem runs in M5

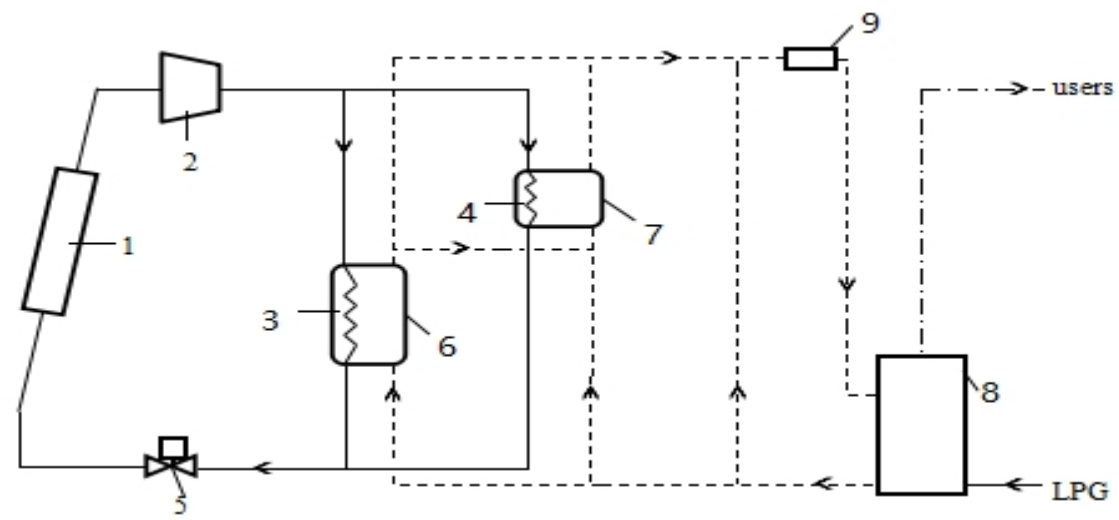

1 collector/evaporator; 2 compressor; 3 first condenser; 4 second condenser; 5 expansion valve; 6 water tank;

7 phase change heat storage water tank; 8 vaporizer; 9 auxiliary heat source

Fig.1 Schematic diagram of DX-SAHPV with PCM

\section{PCM and heat storage cycle}

We choose paraffin with $10 \%$ expanded graphite as the PCM for DX-SAHPV due to its advantages in both thermal storage performance and price. Because the system is used to supply daily gas for residents, a one-day heat storage cycle is applied in this study. 


\section{Structure design of phase change heat storage device}

\section{Shape determination of the phase change heat storage device}

Comparing with rectangular and spherical, the cylindrical heat storage water tank is more reasonable and practical, therefore, the cylindrical water tank is used in this system.

\section{The Size Determation of Spherical Heat Storage Modules.}

Stainless steel is used as the encapsulation material of spherical heat storage unit because of the non-corrosiveness for paraffin to metal [6]. In this study, heat storage and release processes of the spherical heat storage unit under different radiuses have been simulated and analyzed by the melt/solidification model of Fluent software, respectively, and the heat storage/release time, temperature distribution and variation of liquid fraction have been obtained.

Fig.2 shows the heat storage/release time of the spherical heat storage unit under different radiuses. It can be seen that the heat storage/release time increasing with the increase of radius and the heat release time is always larger than the heat storage time. This is mainly because that during the melting process of PCM, the convective heat transfer happening in the outer layer of the unit enhances the heat transfer between the unit and PCM. It can also be found that the heat storage time almost increases linearly with the increase of the radius from $30 \mathrm{~mm}$ to $60 \mathrm{~mm}$ and the slope of the variation curve increases from $60 \mathrm{~mm}$ to $80 \mathrm{~mm}$. In addition, considering some factors, such as the space of the heat storage water tank filled with the spherical heat storage units, manufacture method etc, the spherical stainless steel unit with the radius of $30 \mathrm{~mm}$ is selected. When the heat transfer temperature difference is $3{ }^{\circ} \mathrm{C}$, its heat storage and relaese time are $9200 \mathrm{~s}$ and $16500 \mathrm{~s}$, respecitvely.

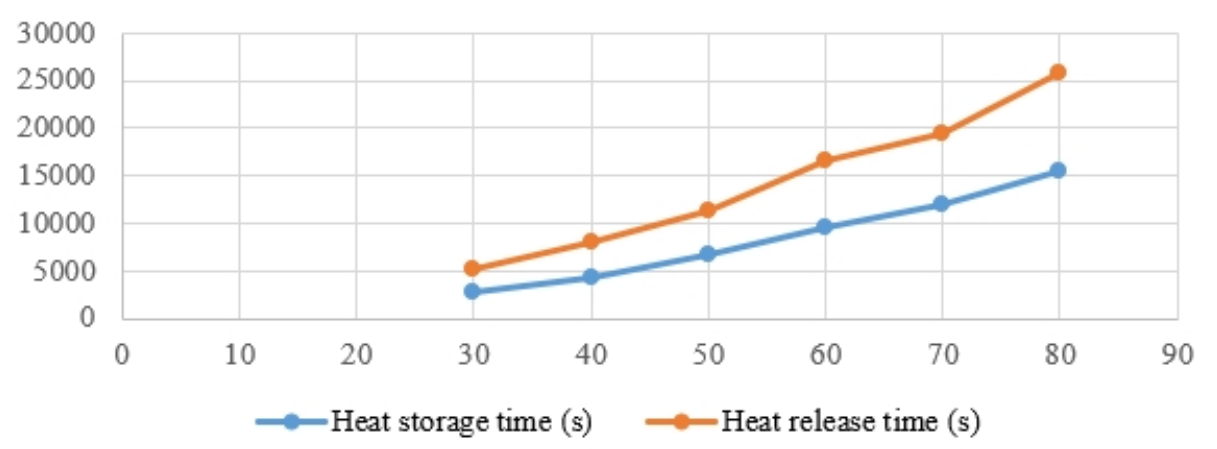

Fig.2 Heat storage/ release time of the spherical heat storage unit under different radius

Table 2 reports the detailed heat storage and release process of an unit with the radius of $60 \mathrm{~mm}$. It can be seen that the melting rate of heat storage unit is becoming faster and faster, which main reason is that the convection heat is increasing with the rise of the liquid phase rate. It also presents that the solidification rate of heat storage unit is becoming faster and faster, which is mainly due to the fact that the heat conduction is increasing with the rise of liquid fraction. The heat storage process was simulated under the assumptions that the wall temperature was constant and the temperature difference was $3{ }^{\circ} \mathrm{C}$. But, in actual, there is convection heat transfer between the wall and the PCM and the temperature difference is more than $3{ }^{\circ} \mathrm{C}$. Hence, the storage/release time should be relatively shorter. 
Table 2 Heat storage (release) process of a PCM sphere with the radius of $60 \mathrm{~mm}$

\begin{tabular}{|c|c|c|c|}
\hline \multicolumn{2}{|c|}{ Heat storage process } & \multicolumn{2}{|c|}{ Heat release process } \\
\hline $\begin{array}{c}\text { the changing liquid phase } \\
\text { rate }\end{array}$ & temperature distribution & $\begin{array}{c}\text { the changing liquid phase } \\
\text { rate }\end{array}$ & temperature distribution \\
\hline $\begin{array}{l}E \\
E \\
E \\
E\end{array}$ & 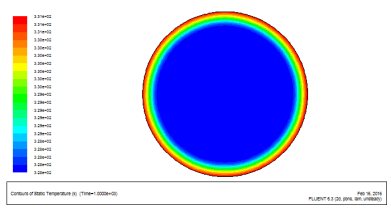 & 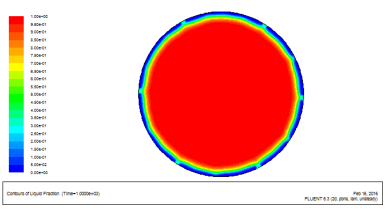 & 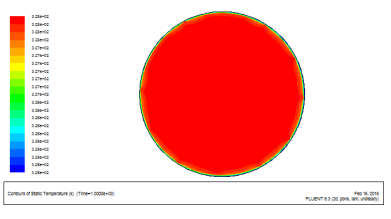 \\
\hline 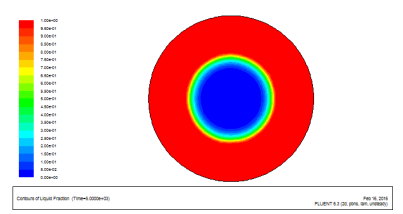 & 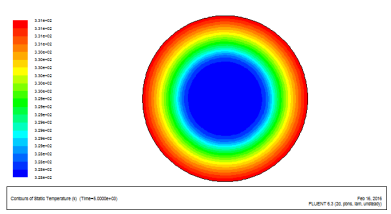 & 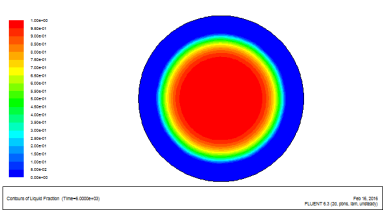 & 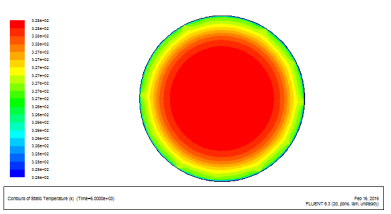 \\
\hline 政 & 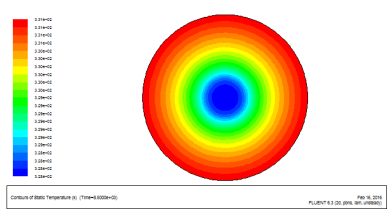 & 政 & 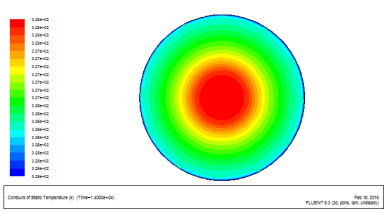 \\
\hline 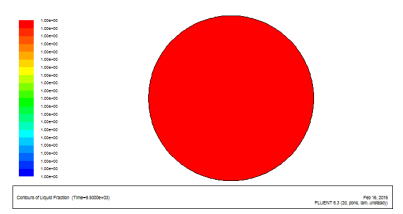 & 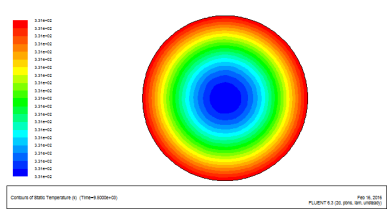 & $\begin{array}{l}E \\
E \\
E \\
E \\
E\end{array}$ & 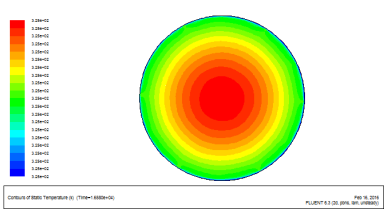 \\
\hline
\end{tabular}

\section{Configuration of heat exchanger.}

In order to enhance the heat transfer and to facilitate the configuration of the spherical heat storage unit, the spiral tube heat exchanger is adopted.

Fig. 3 presents the schematic diagram of the phase change heat storage device. The refrigerant enters the collector/evaporator at the given pressure and temperature and is vaporized by absorbing solar and/or ambient energy. Then the refrigerant vapour at a high temperature passes through the compressor. Sequentially, the vapor at a high temperature and pressure flows into the phase change hot storage water tank and releases heat to the water, and then the heat is absorbed and stored in the PCM. The refrigerant is then throttled by the thermostatic expansion valve and flows back to the collector/evaporator. At the same time, the water enters the latent heat storage tank after releasing heat in the vaporizer, and the PCM starts to release heat to heat the water. 


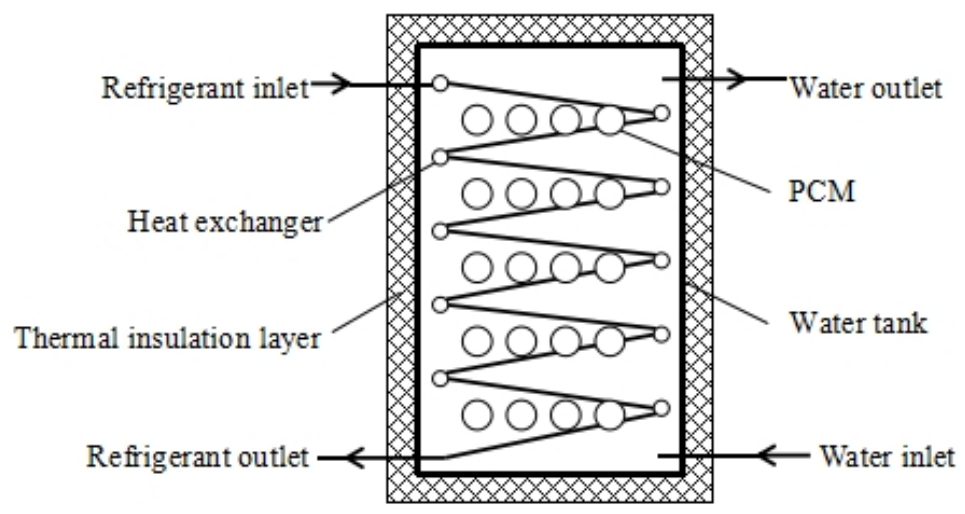

Fig. 3 Schematic diagram of phase change heat storage device

\section{Determination of heat storage capacity of PCM heat storage device}

It is very important to determine the heat storage capacity of the PCM heat storage device. It is mainly because that it has a significant impact on both the economy and the energy efficiency.

Fig.4 shows the annual heat production variation of DX-SAHP and auxiliary heat source in DX-SAHPV proposed in [1]. It illustrates that the monthly heat produced by the auxiliary heat source varies from 600 to $3000 \mathrm{MJ}$, the mean value is in the range of 20-100 MJ daily.

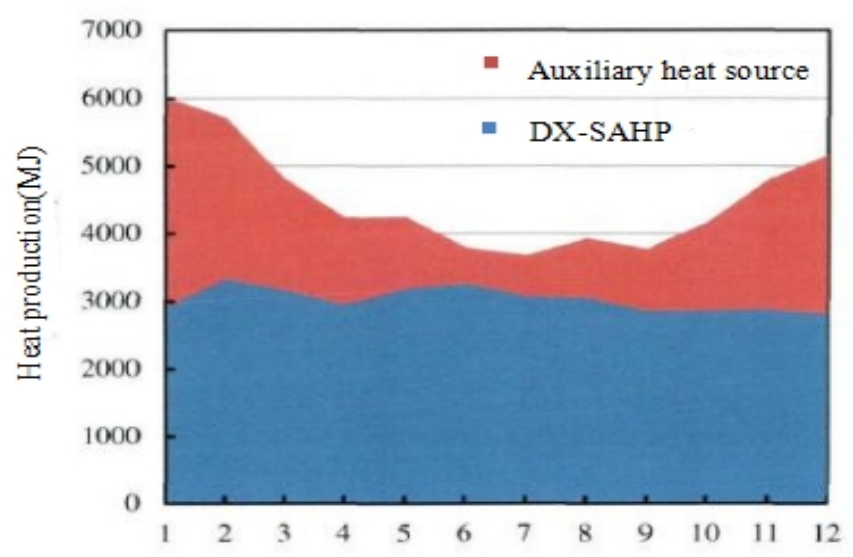

Fig.4 Annual heat production variation of DX-SAHP and auxiliary heat source

The results indicate that a great improvement in both the utilization of solar energy and DX-SAHP is achieved by the application of phase change heat storage device, and also a reduction in energy consumption of the auxiliary heat source. The heat storage capacity of the phase change heat storage device is determined by the heat production of the auxiliary heat source that is in the range of 20-100 MJ. There is lower investment and higher using rate cost of the thermal storage device in the smaller heat storage capacity. But the required heating load supplied by auxiliary heat source is higher, which will lead to the higher operation cost. Considering the investment cost and operation cost, an economical analysis on the heat storage capacity of the phase change heat storage tank is taken.

(1) Operation cost which is saved per year is calculated from Eq.(1)

$$
C_{\mathrm{OS}, \text { Eaux }}=C_{\mathrm{OF}, \text { Eaux }}-C_{\mathrm{O}} \text {. }
$$


where $C_{\text {os,Eaux }}$ is the operation cost of the original system that only use electric water heater as auxiliary heat source, $C_{\mathrm{o}}$ is the annual operation cost of phase change heat storage tank.

(2) Recovery period is calculated from Eq.(2) [7]:

$$
Y=\frac{C_{\mathrm{IC}}}{C_{\text {OS,Eaux }}}
$$

where $C_{\mathrm{IC}}$ is the initial investment cost of phase change heat storage tank.

Fig.5 illustrates the initial investment cost, annual operation cost and total cost of the phase change heat storage tank under different heat storage capacities. It can be seen that the annual investment cost gradually increasing with the rising heat storage capacity. The trend that the annual investment cost increases is relatively small when the heat storage capacity increases from $20 \mathrm{MJ}$ to $40 \mathrm{MJ}$, but relatively large from $40 \mathrm{MJ}$ to $60 \mathrm{MJ}$. In contrast, the annual operating cost of the phase change heat storage tank decreases with the rising heat storage capacity. The reduction of the annual operating cost is relatively large when the heat storage capacity increases from $20 \mathrm{MJ}$ to $40 \mathrm{MJ}$, but is relatively small and nearly declines linearly from $40 \mathrm{MJ}$ to $60 \mathrm{MJ}$.

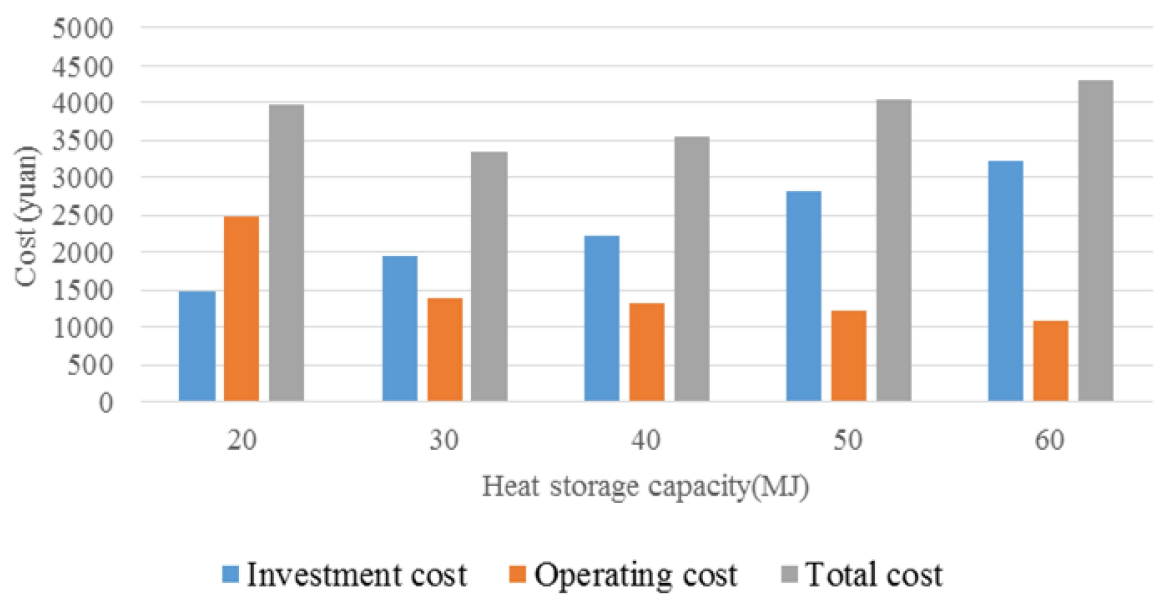

Fig.5 Annual investment cost, operating cost and total cost under different heat storage capacities

Table 3 shows the quantitative economic analysis of the heat storage modules of different PCM storage capacity. We can see that the payback period decreases firstly and then increases with rising the values of the storage capacity. When the storage capacity is $40 \mathrm{MJ}$, it has the minimum payback period of 1.4 years. Therefore, $40 \mathrm{MJ}$ is an optimal capacity value for the heat storage device.

Table 3 Economic analysis of the phase change heat storage tank

\begin{tabular}{cccccc}
\hline Heat capacity of PCM [MJ] & 20 & 30 & 40 & 50 & 60 \\
\hline Annual operating cost savings [RMB Yuan] & 1068 & 1602 & 2136 & 2336 & 2483 \\
Payback period [year] & 2.0 & 1.6 & 1.4 & 1.5 & 1.6 \\
\hline
\end{tabular}

\section{Conclusions}

In this study, theoretical analysis and numerical simulation on the phase change thermal storage device for DX-SAHPV are made. The main conclusions are as follows: 
1) The spherical water tank is selected as the phase change heat storage device because it is internally provided with a spiral tube heat exchanger and its temperature distributes uniformly. Taking into account the heat storage time and the processing technology, $60 \mathrm{~mm}$ is the optimal radius of heat storage unit for the spherical thermal storage water tank.

2) The economic analysis is made to determine the heat storage capacity of the phase change heat storage tank. The phase change heat storage capacity of $40 \mathrm{MJ}$ has the shortest payback period of 1.4 years.

\section{Acknowledgements}

The authors greatly acknowledge the financial support from the Natural Science Foundation of Hebei Province (E2016502027), the Scientific Research Project of Education Department of Hebei Province (Z2015119) and the Fundamental Research Funds for the Central Universities (2017MS124).

\section{References}

[1] Guohua Shi, Research on LPG Vaporization System Utilizing Solar Assisted Heat Pump, D. Baoding: North China Electric Power University, 2015.

[2] Shilin Qu, Li Peng, Xiaoqiong Wu, Lixiang Yang, Design of phase change thermal storage device in the thermal utilization of solar energy, J. Journal of Solar Energy. 36(2015) 1705-1709.

[3] Lianxiang Ma, Yan Lin, Jianghui Zhang, Hongcai Zheng, Yan He, Research of the influence of phase change thermal storage applied in direct-expanding solar heat pump, J. Journal of Solar Energy. 35(2014) 285-289.

[4] Shilin Qu, Lixiang Yang, Li Peng, Jiaguo Hu, Performance of Solar Energy Automatic Control System Assisted Dual Water Tank with Phase Change Materials and Heat Pump, J. Journal of Tianjin University. 47(2014) 42-46.

[5] Guohua Shi, Shengnan Tian, Dan Li, A heat storage of solar assisted heat pump vaporization liquefied petroleum gas system, China Patent 2016200944135. (2016)

[6] Xi Wang, Yanping Yuan etc., Design of Water Tank with Phase Change Materials Storing Heat from Hot Water or Electricity, J. Refrigeration and Air Conditioning. 25(2011) 113-116.

[7] Hong Li, Simulation and Experimental Investigation on Optimum Application of Multi-functional Solar Assisted Air Source Heat Pump Systems, D. Hong Kong: The Hong Kong Polytechnic University, 2010. 